\title{
Непролиферативные и пролиферативные поранения женской репродуктивной системы крыс и мышей
}

(по материалам Проекта INHAND (Международная гармонизация номенклатуры и диагностических критериев поражения крыс и мышей) D. Dixon, R. Alison, U. Bach et al. Nonproliferative and Proliferative Lesions of the Rat and Mouse Female Reproductive System.

J. Toxicol Pathol. 2014. V. 27 (3\&4 Suppl). 1S-107S

\section{II. Яичники}

А. Непролиферативные поражения амилоида (N) яичника (рис. 29)

Вид

Мышь

Синонимы

Амилоидоз

Патогенез/клетка происхождения. Внеклеточное осаждение полипептидных фрагментов гликопротеинов сыворотки; белки находятся в конформации $\beta$-складчатого листа. Может быть результатом пролиферирующих нарушений В-клеток или вторичным по отношению к воспалительному процессу.

Диагностические признаки. Накопление внеклеточного, аморфного, бесклеточного светло-эозинофильного до бледного материала в периваскулярных пространствах или междоузлиях яичника, внутри желтых тел и внутри атретических фолликулов. Может быть в тонких полосах или плотных листах. Может заменить целые области органа.

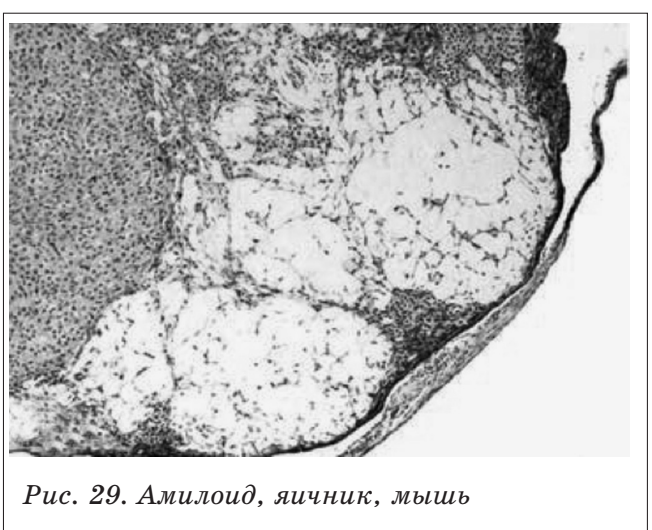

Может вызвать увеличение массы или покоричневение яичника. Часто встречается в более чем одном органе (системное заболевание).

Специальные летоды диагностики. Окрашивание Конго Красным амилоида позволяет выявить его по зеленому двулучепреломлению в поляризованном свете.

Дифференциальные диагнозы. Отложение фибрина:

- фибринозные экссудаты выглядят как имеющие фибриллярную структуру;

- обычно не системно.

Фибриноиднье изменения:

- осаждение интенсивно эозинофильных белков плазмы в стенках сосудов;

- иногда присутствуют фрагменты клеток;

- могут сопровождаться кровоизлиянием или тромбозом.

Коллентарий. Амилоидоз, как правило, является естественным заболеванием у мышей и включает в себя осаждение преимущественно легких цепей иммуноглобулина; он распространен у стареющих мышей и был индуцирован системно у мышей при хроническом введении оксазепама. Заболеваемость варьирует в зависимости от линии животных - линии SJL, C57Bl и CD-1 предрасположены, а $\mathrm{C} 3 \mathrm{H}$ и $\mathrm{A} / \mathrm{J}$ являются относительно устойчивыми. Крысы, как правило, очень устойчивы. Вторичный амилоидоз связан с хроническими воспалительными поражениями, которые приводят к синтезу SAA (сывороточного амилоида А) в печени.

*Продовження, початок у Т. 13, № 2, С. 146-154. 
31)

Ангиэктазис (N), Яичники (рис. 30 и

Buд

Мышь, Крыса

Синонимы

Сосудистая эктазия, Telangiectasis

Патогенез/клетка происхождения. Расширение ранее существовавших кровеносных сосудов.

Диагностические признаки:

- местная кистозная дилатация ранее существовавших сосудов;

- пораженные сосуды, кистозные и заполненные кровью, присутствуют в интерстиции, особенно вблизи хилуса или в фолликулах, или в желтых телах;

- может искажать обычную архитектуру;

- количество сосудов не увеличивается;

- может быть связан с тромбозом, кровоизлиянием или воспалением;

- ядра эндотелиальных клеток сплющены и клетки прядеобразные (spind loid), как в нормальной сосудистой сети. Нет доказательств клеточного плеоморфизма;

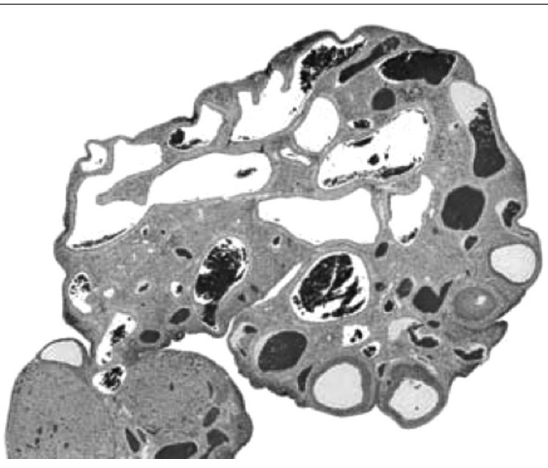

Рис. 30. Ангиэктаз, яичник, крыса

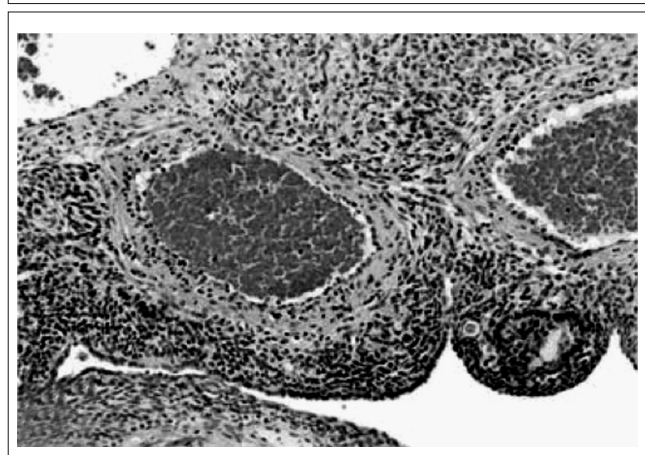

Рис. 31. Ангиэктаз, яичник, крыса
- эндотелиальные клетки образуют один слой.

\section{Дифференциальные диагнозы.}

Гемангиома:

- увеличение количества эндотелиальных, заполненных кровью пространств;

- эндотелиальные клетки имеют гипертрофированные ядра;

- митозы могут присутствовать;

- может присутствовать слабый клеточный плеоморфизм или ядерная атипия.

Гиперплазия ангиоматозная:

- увеличение количества близко расположенных мелких кровеносных сосудов;

- ядра эндотелиальных клеток преимущественно сплющены;

- эндотелиальные клетки образуют один слой;

- маленькая поддерживающая строма. Кровотечение:

- кровь экстраваскулярная;

- сосуды не являются кистозными.

Закупорка:

- количество кровеносных сосудов не увеличивается;

- другие ткани/органы могут быть затронуты.

Колментарий. Более распространен у мышей, чем у крыс. Может быть связан с кистами яичников. Дифференциация ангиоэктаза от ангиоматозной гиперплазии и гемангиомы иногда затруднена.

Киста бурсальная (N), яичник (рис. 32) Bud

Мышь, Крыса

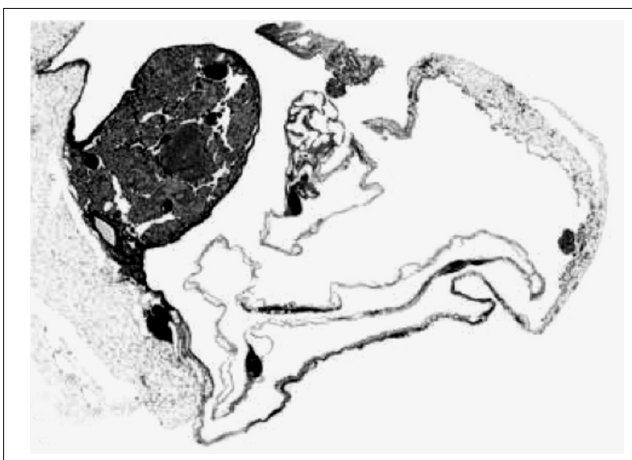

Рис. 32. Бурсальная киста, яичник, мышь 
Патогенез/клетка происхождения. Отличать от овариальной бурсы с жидкостью.

Диагностические признаки:

- выстелена простым плоскоклеточным эпителием;

- киста окутывает яичник и может вызвать сжатие, но не находится в яичнике.

Дифференциальные диагнозы.

Киста фолликулярная:

- присутствует в яичнике;

- выстелена (от одного до нескольких слоев) кубическими или сплющенными гранулезными клетками, покоящимися на тонкой стенке и часто окруженными текальными клетками.

Киста rete ovarii:

- присутствует в пределах hilus/ medulla и/или рядом с яичником;

- есть соединение с hilus яичников;

- выстелена сплюснутым, кубическим или столбчатым эпителием, часто с апикальной цитоплазмой;

- эпителий может быть реснитчатым;

- может быть присоединение к параовариальным структурам в мезоварии.

Киста параовариальная:

- выстелена сплюснутым, кубическим или столбчатым эпителием; довольно часто имеющим апикальные ядра;

- эпителий может быть реснитчатым;

- нет связи с внутриовариальными или внутрипочечными структурами.

Киста лютеальная:

- присутствует в яичнике;

- выстелена по меньшей мере частично лютеинизированными гранулезными клетками.

Киста неспецифическая:

- если источник или тип кисты яичника не является очевидным, термин неспецифическая киста может быть наиболее подходящим диагнозом.

Фолликул, лютеинизированный, кистозный:

- присутствует в яичнике;

- выстелен одним или несколькими слоями кубических или сплющенных гранулезных клеток, покоящихся на тонкой стенке и часто окруженных текальными клетками;
- частичная лютеинизация гранулезных клеток, выстилающих стенки;

- лютеинизация часто асимметрична в стенке кисты;

- вырожденную яйцеклетку иногда можно наблюдать в пределах полости кисты, что и подтверждает диагноз. Киста эпителиальная:

- присутствует в яичнике;

- выстелена сплющенным кубовидным (до нижнего столбчатого) эпителием;

- соединение с поверхностным эпителием яичника является очевидным.

Коллентарий. Более распространена у мышей, чем у крыс. Бурса - это расширение mesosalpinx и выстилается простым плоскоклеточным эпителием (мезотелий). У крыс и мышей есть полная бурса, которая полностью окутывает яичник. Бурсальные кисты часто наблюдаются при макроскопии, но не могут быть идентифицированы гистологически, потому что они часто разрываются во время сбора материала или его обработки.

Киста эпителиальная (N), яичник (рис. 33 и 34)

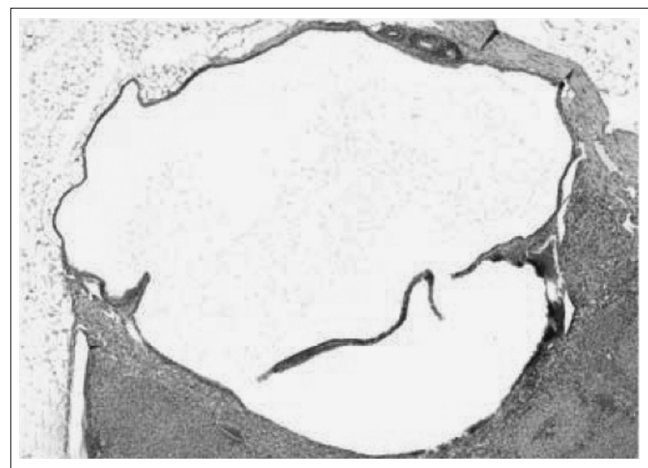

Рис. 33. Эпителиальная киста, яичник, мышь

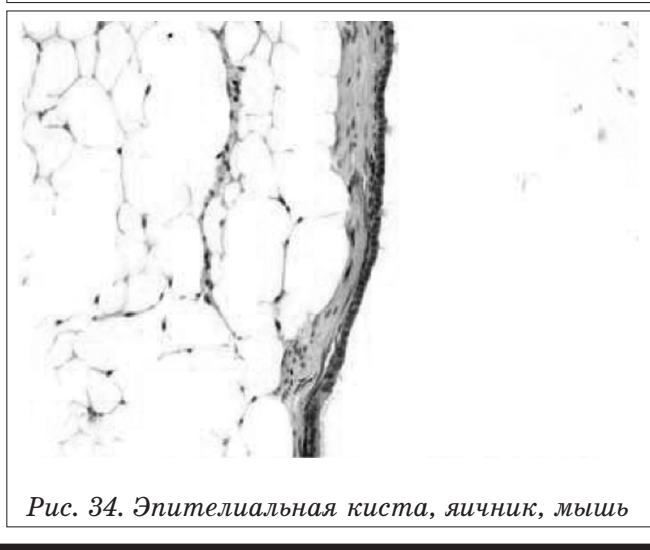


Вид

Мышь, Крыса

Синонимы

Киста простая, Киста эпидермоидная, Кистозное эпителиальное включение

Патогенез/клетка происхождения. Эпителиальные кисты, как полагают, возникают из-за роста поверхностного эпителия яичника.

Диагностические признаки:

- кисты выстланы сплющенным кубическим (до нижнего столбчатого) эпителием. Некоторые могут напоминать эпителий поверхности яичников;

- интравариантные кисты, выровненные сплюснутым, кубическим или столбчатым эпителием. Кубовидные и столбчатые клетки могут быть ресничными;

- некоторые кисты могут содержать папиллярные выпячивания эпителия без сложного разветвления (папиллярная гиперплазия);

- большинство кист, как правило, расположены в области коры;

- наличие и количество кист увеличивается с возрастом;

- есть контакт с поверхностным эпителием;

- отсутствие видимой связи с параовариальными или сетевыми структурами. Дифференциальные диагнозы.

Киста фолликулярная:

- выстлана от одного до нескольких слоев кубовидными или сплюснутыми гранулезными клетками, покоящимися на тонкой стенке и часто окруженными текальными клетками;

- может искажать архитектуру яичников;

- больший размер, чем у нормального позднего третичного фолликула;

- может содержать дегенерирующий ооцит.

Фолликул, лютеинизированный, кистозный:

- присутствует в яичнике;

- выстлан от одного до нескольких слоев кубовидными или сплюснутыми гранулезными клетками, покоящимися на тонкой стенке и часто окруженные текальными клетками;
- частичная лютеинизация гранулезных клеток, выстилающих стенку;

- лютеинизация часто асимметрична в стенке кисты;

- вырожденную яйцеклетку иногда можно наблюдать в полости кисты, что и подтверждает диагноз;

- больший размер, чем у нормального позднего третичного фолликула.

Киста rete ovarii:

- присутствует рядом с яичником или внутри него, часто на хилусе;

- если они присутствуют в структурах, прилегающих к яичнику, должно быть очевидно соединение с яичником;

- выстлана сплюснутым, кубическим или столбчатым эпителием; часто имеют апикальные ядра;

- эпителий может быть ресничным;

- можно увидеть соединение с параовариальными структурами в мезовариуме;

- обычно искажает архитектуру яичников.

Киста параовариальная:

- выстлана сплющенным, кубическим или столбчатым эпителием;

- эпителий может быть ресничным;

- может быть связана с гладкой мышцей;

- отсутствует связь с внутриовариальными или внутригрудными структурами.

Киста бурсальная:

- обертывает яичник, но не присутствует в пределах его самого;

- выстлана простым плоскоклеточным эпителием.

Цистоаденома:

- papillae имеют очаговое происхождение со сложным разветвлением; могут проявлять легкую атипию и быть больше, чем размер желтого тела.

Киста неспецифическая:

- если источник или тип кисты яичника не является очевидным, термин неспецифическая киста может быть наиболее подходящим диагнозом. Киста лютеиновая:

- присутствует в яичнике;

- выстлана лютеинизированными гранулезными клетками;

- больше, чем нормальное желтое тело. 
Колментарий. Эпителиальные кисты чаще встречаются у мышей, чем у крыс. Экспрессия цитокератина 8 в эпителиальных кистах может помочь отличить их от фолликулярных кист. Суперовуляция мышей индуцирует увеличение числа кортикальных и/или центральных эпителиальных кист яичников. У мышей кистозный эпителий экспрессирует рецепторы эстрогена и прогестерона. Без очевидной связи с поверхностным эпителием трудно отличить от других кист яичников, связанных с эпителием (те, которые относятся к реестру). Если соединение с поверхностным эпителием яичника не является очевидным, то термин «неспецифическая киста» более уместен.

Киста фолликулярная (N), яичник (рис. 35 и 36)

Вид

Mыциь. Крыса

Патогенез/клетка происхождения. В целом, фолликулярные кисты развиваются в результате гормонального дисбаланса или дисрегуляции гипоталамо-гипофизарной оси и приводят к срыву овуляции.

Диагностические признаки:

- тонкостенные, заполненные бледноацидофильным (до амфифильного) остатком или кровью; могут также содержать клеточные обрывки, дегенерирующие ооциты или пенистые, вакуолизированные или нагруженные макрофаги;

- обычно выстланы от одного до четырех слоев кубовидными гранулезными клетками; без лютеинизации;

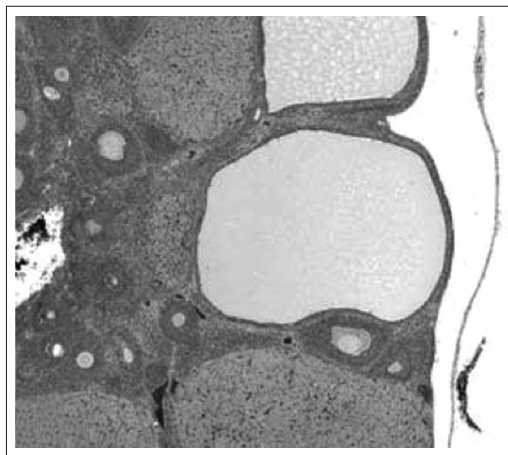

Рис. 35. Фолликулярная киста, яичник, крыса
- большие кисты могут быть выстланы одним слоем сплюснутых клеток, опирающихся на тонкую волокнистую капсулу;

- часто возникает дегенерация отдельных гранулезных клеток;

- может присутствовать одиночная или множественная киста;

- вырожденную яйцеклетку иногда можно наблюдать в полости кисты;

- больший размер, чем у нормального позднего третичного (превуляторного) фолликула.

\section{Дифреренциальные диагнозы.}

Поздний третичный (превуляторный) фолликул:

- содержит ооцит и хорошо развитый слой текальных клеток;

- отсутствие признаков апоптоза/атрезии гранулезных клеток.

Атретический поздний фолликул:

- похож по внешнему виду на фолликулярные кисты, но меньшего размера (не более, чем нормальный поздний третичный фолликул);

- содержит дегенерирующий ооцит (но ооцит может не быть виден в плоскости сечения);

- в гранулезных клетках есть апоптоз. Фолликул, лютеинизированный (+/модифицированный кистозный):

- стенка, состоящая из гранулезных клеток с нерегулярными скоплениями или групп крупных, круглых и многоугольных лютеинизированных клеток;

- иногда в фолликуле можно наблюдать вырожденный ооцит;

- лютеинизированный фолликул не превышает по размеру нормальный поздний третичный фолликул;

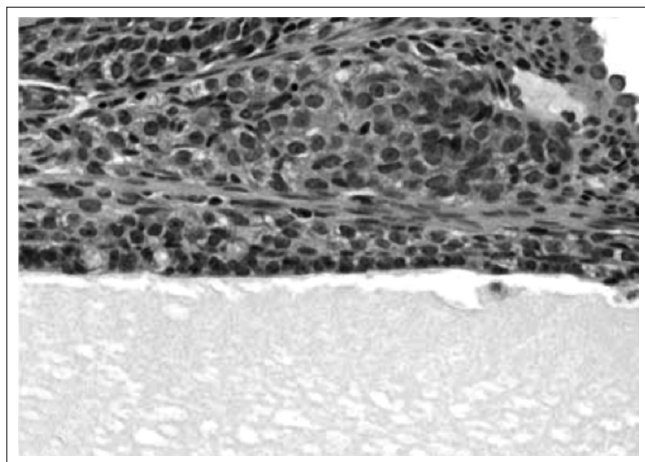

Рис. 36. Фолликулярная киста, яичник, крыса 
- кистозный лютеинизованный фолликул больше, чем обычный поздний третичный фолликул и имеет кистозный центр.

Киста лютеиновая:

- выстлана от одного до нескольких слоев крупными многоугольными лютеинизированными клетками.

- больше по размеру, чем нормальное желтое тело.

Киста, эпителиальная:

- присутствует в яичнике;

- выстлана сплющенным кубовидным до нижнего столбчатого эпителием;

- соединение с поверхностным эпителием яичника является очевидным.

Колментарий. Фолликулярные кисты являются обычным явлением у интактных крыс и мышей, особенно с возрастом, а частота их возникновения также зависит от линии животных. У более старых крыс, когда цикл яични- ков удлиняется, некоторые предовуляторные фолликулы, по-видимому, теряют способность овулировать в периоды персистентного эструса. У молодых крыс фолликулярные кисты могут развиваться в сочетании с дисбалансом тиреоидного гормона, пролактина, лютеинизирующего гормона или андрогенов. Фолликулярные кисты также могут быть результатом факторов, которые изменяют секрецию гонадотропинов или овариальные ответы на них. Некоторые фолликулы могут продуцировать эстрадиол и могут быть связаны с персистентным эструсом.

Матеріал підготували: Л. Б. Бондаренко, А. В. Матвієнко, ДУ «Інститут фарлакологї та токсикологї НАМНУ» 